\title{
Sistem Pendukung Keputusan Pengangkatan Guru Tetap Menerapkan Metode Weight Aggregated Sum Product Assesment (WASPAS)
}

\author{
Safrizal Barus ${ }^{1}$, Vera Meikana Sitorus ${ }^{1}$, Darmawan Napitupulu ${ }^{2}$, Mesran $^{3}$, Supiyandi $^{4}$ \\ ${ }^{1}$ Program Studi Sistem Informasi, STMIK Nusa Mandiri Jakarta, Indonesia \\ ${ }^{2}$ Pusat Penelitian Sistem Mutu dan Teknologi Pengujian Lembaga Ilmu Pengetahuan Indonesia, Indonesia \\ ${ }^{3}$ STMIK Budi Darma, Medan, Indonesia \\ ${ }^{4}$ Universitas Pembangunan Panca Budi Medan, Indonesia
}

\begin{abstract}
Abstrak
Evaluasi terhadap para guru honorer merupakan kegiatan yang umum disekolah menengah atas ataupun kejuruan. Hal ini berguna untuk mengetahui hasil pengajaran guru honorer kepada siswanya. Penilaian, evaluasi dan pemberian penghargaan dapat dilakukan bertujuan untuk memacu kinerja dari para guru dalam proses belajar mengajar sehingga meningkatkan prestasi guru, penilaian dilakukan untuk memperoleh guru honor yang berprestasi yang kemudian akan diangkat menjadi guru tetap. Dalam penentuan urutan pengangkatan guru tetap, sering muncul subjektif dari para pengambil keputusan, sehingga terdapat masalah-masalah dan hal ini menyebabkan susahnya dalam menentukan calon guru tetap. Untuk menentukan rekomendasi guru tetap dapat digunakan metode Weight Aggregated Sum Produck Assesment (WASPAS). Metode WASPAS dapat digunakan untuk proses perangkingan guru honor yang berprestasi dengan kriteria-kriteria yang telah ditentukan.
\end{abstract}

Kata kunci: Pengangkatan Guru Tetap, Sistem Pendukung Keputusan, WASPAS

\begin{abstract}
Evaluation of honorary teachers is an activity that is generally high school or vocational. It is useful to know the results of teaching honorary teachers to their students. Assessment, evaluation and rewarding can be done to spur the performance of the teachers in teaching and learning process so as to improve teacher achievement, the assessment is done to obtain the honorable teachers who will be appointed as permanent teachers. In determining the order of permanent appointment of teachers, it often appears subjective from the decision-makers, so that there are problems and this causes the difficulty in determining prospective teachers. To determine the recommendation of the teacher can still be used the method of Weight Aggregated Sum Production Assessment (WASPAS). WASPAS method can be used to process the honorarium of honor teachers with the criteria that have been determined.
\end{abstract}

Keywords: Teacher Appointment, Decision Support System, WASPAS

\section{PENDAHULUAN}

Kegiatan penilaian dan evaluasi terhadap para guru honor merupakan kegiatan yang umum disekolah menengah atau kejuruan. Hal ini berguna untuk mengetahui hasil pengajaran guru honor kepada siswanya. Penilaian, evaluasi dan pemberian penghargaan dapat dilakukan bertujuan untuk memacu kinerja dari para guru dalam proses belajar mengajar sehingga meningkatkan prestasi guru, penilaian dilakukan untuk memperoleh guru honor yang berprestasi yang kemudian akan diangkat menjadi Guru Tetap. Penentuan guru honor berprestasi memiliki nilai yang telah ditetapkan oleh pihak sekolah, calon guru yang dinilai adalah guru honor yang tlah mengajar selama lebih dari satu tahun. Keputusan pengangkatan guru tetap tersebut dilakukan setiap akhir semester genap dengan mengevaluasi setiap akhir semester genap dengan mengevaluasi kinerja guru honorer yang berprestasi. Untuk memudahkan dalam pengangkatan guru tetap, maka diperlukan suatu sistem yang dikenal dengan nama sistem pendukung keputusan (SPK). SPK bertujuan untuk membantu pengambil keputusan dalam menghasilkan suatu keputusan. Beberapa metode dapat diterapkan dalam SPK tersebut, misalnya, WASPAS, ELECTRE, VIKOR, PROMETHEE[1][2].

Penelitian terdahulunya yaitu penentuan pencapaian prestasi guru honor adalah masalah penentuan guru honor yang dianggap berprestasi, upaya yang dilakukan yaitu dengan membangun sebuah sistem pendukung keputusan yang menghasilkan keluaran yang membantu menyelesaikan keluaran yang membantu menyelesaikan masalah dalam mengambil keputusan terhadap beberapa alternatif yang harus diambil dengan kriteria yang menjadi bahan pertimbangan, metode yang digunakan yaitu metode Analyties Hierarchy Procces (AHP) sebagai pemberian bobot kriteria dan Simple Addative Weighting (SAW) sebagai rangking calon guru tetap[3].

Pada penelitian ini, metode yang diterapkan untuk menghasilkan keputusan pengangkatan guru tetapyaitu Weight Aggregated Sum Produck Assesment (WASPAS). Metode tersebut dipilih karena model pendukungan keputusan dimana peralatan utamanya adalah sebuah hirarki fungsional dengan pemasukan utamanya persepsi manusia, yakni dalam hal ini adalah orang yang ahli dalam masalah atau orang yang mengerti permasalahan seleksi penerimaan guru honor. 


\section{TEORITIS}

\subsection{Guru}

Menurut undang-undang 14 tahun 2005, Guru adalah pendidik profesional dengan tugas utama mendidik, mengajar, membimbing, mengarahkan, melatih, menilai dan mengevaluasi peserta didik pada pendidikan anak usia dini melalui jalur formal pendidikan dasar dan pendidikan menegah. Pengertian guru diperluas menjadi pendidik yang dibutuhkan secara dikotomis tentang pendidikan. Dijelaskan pada ayat 2 yakni pendidik merupakan tenaga profesional yang bertugas merencanakan dan melaksanakan proses pembelajaran[4].

\subsection{Weight Aggregated Sum Product Assesment(WASPAS)}

WASPAS adalah metode yang dapat mengurangi kesalahan-kesalahan atau mengoptimalkan dalam penaksiran untuk pemililahan nilai tertinggi dan terendah. Demikian,Tujuan utama pendekatan MCDM adalah memilih opsi terbaik dari sekumpulan alternatif di hadapan berbagai kriteria yang saling bertentangan. Dalam tulisan ini, sebuah usaha dilakukan[5].

Untuk membenarkan ketepatan penerapan dan ketepatan pendekatan MCDM yang hampir baru, yaitu metode penilaian jumlah agregat berbobot (WASPAS).

Langkah proses perhitungan menerapkan metode WASPAS[6], yaitu:

1. Buat sebuah matriks keputusan

$x=\left[\begin{array}{cccc}x_{11} & x_{12} & \cdot & x_{1 n} \\ x_{21} & x_{11} & \cdot & x_{2 n} \\ \cdot & \cdot & \cdot & \cdot \\ x_{m 1} & x_{m 1} & \cdot & x_{m n}\end{array}\right]$.

2. Melakukan normalisasi terhadap matrik $\mathrm{x}$

Kriteria Benefit

$\bar{x}_{i j}=\frac{x_{i j}}{\max _{i} x_{i j}}$

Kriteria Cost

$\bar{x}_{i j}=\frac{\min _{i} x_{i j}}{x_{i j}}$.

3. Menghitung nilai Qi

$$
\mathrm{Qi}=0,5 \sum_{j=1}^{n} X i j w+0,5 \prod_{j=1}^{n}(x i j)^{w j} \ldots
$$

Dimana :

$\mathrm{Q}_{\mathrm{i}} \quad=$ Nilai dari $\mathrm{Q}$ ke $\mathrm{i}$

$\mathrm{X}_{\mathrm{ij}} \mathrm{W}=$ Perkalian nilai $\mathrm{X}_{\mathrm{ij}}$ dengan bobot $(\mathrm{w})$

$0,5 \quad=$ Ketetapan

Alternatif yang terbaik merupakan alternatif yang memiliki nilai Qi tertinggi.

\section{ANALISA DAN PEMBAHASAN}

Pada proses penerimaan pelamar dibutuhkan sistem yang dapat membantu dalam membuat suatu keputusan untuk calon guru honor dengan cepat dan tepat. Untuk meringankan kerja kepala sekolah menentukan calon guru honor. Penilaian setiap pelamar terhadap kriteria-kriteria yang ada dilakukan dengan model penilaian yang bersifat kuantitatif. Salah satu metode perhitungan kuantitatif tersebut adalah metode WASPAS.

Pada tahap awal pemecahan permasalahan, terleih dahulu menentukan jenis-jenis kriteria dalam pemilihan pelamar dalam mengikuti penerimaan guru honor. Kriteria-kriteria yang dibutuhkan dalam seleksi guru honor adalah tingkat kesarjanaan Ijazah,Indeks Prestasi Kumulatif(IPK), memiliki ilmu didaktif dan metodik, pengalaman mengajar, usia dan jarak dan tempat tinggal dengan sekolah.

Berikut merupakan tabel kriteria. 
Tabel 1. Kriteria

\begin{tabular}{|c|c|c|c|}
\hline Kriteria & Keterangan & Bobot & Jenis \\
\hline $\mathrm{C}_{1}$ & Indeks Prestasi Kumulatif & $30 \%$ & Benefit \\
\hline $\mathrm{C}_{2}$ & Ilmu Didaktik dan Ilmu Metodik & $20 \%$ & Benefit \\
\hline $\mathrm{C}_{3}$ & Pengalaman Mengajar (tahun) & $20 \%$ & Benefit \\
\hline $\mathrm{C}_{4}$ & Usia (tahun) & $15 \%$ & Benefit \\
\hline $\mathrm{C}_{5}$ & Jarak Tempat Tinggal Dengan Sekolah $(\mathrm{Km})$ & $15 \%$ & Cost \\
\hline
\end{tabular}

Kemudian pengambilan data data yang dijadikan sebagai alternatif, dalam hal ini merupakan data calon guru tetap seperti yang terlihat pada tabel 2.

Tabel 2. Alternatif

\begin{tabular}{|c|c|c|c|c|c|}
\hline Alternatif & $\mathrm{C}_{1}$ & $\mathrm{C}_{2}$ & $\mathrm{C}_{3}$ & $\mathrm{C}_{4}$ & $\mathrm{C}_{\mathrm{S}}$ \\
\hline $\mathrm{A}_{1}$ & 3.50 & 90 & 5 & 29 & 5 \\
\hline $\mathrm{A}_{2}$ & 2.90 & 80 & 3 & 33 & 1 \\
\hline $\mathrm{A}_{3}$ & 3.70 & 70 & 3 & 32 & 3 \\
\hline $\mathrm{A}_{4}$ & 2.75 & 60 & 2 & 36 & 2 \\
\hline $\mathrm{A}_{5}$ & 2.80 & 60 & 1 & 35 & 2 \\
\hline
\end{tabular}

Langkah-langkah metode WASPAS adalah sebagai berikut:

1. Membuat matriks keputusan

$X=\left[\begin{array}{lllll}3.50 & 90 & 5 & 29 & 5 \\ 2,90 & 80 & 3 & 33 & 1 \\ 3,70 & 70 & 3 & 32 & 3 \\ 2,75 & 60 & 2 & 36 & 2 \\ 2,80 & 60 & 1 & 35 & 2\end{array}\right]$

2. Berdasarkan persamaan ke2, melakukan normalisasi matriks $X$

$$
\begin{aligned}
& X 1=3,50+2,90+3,70+2,75+2,80 \\
& A_{11}=3,50 / 3,70=0,945 \\
& A_{21}=2,90 / 3,70=0,783 \\
& A_{31}=3,70 / 3,70=1 \\
& A_{41}=2,75 / 3,70=0,743 \\
& A_{51}=2,80 / 3,70=0,756 \\
& X 2=90+80+70+60+60 \\
& A_{11}=90 / 90=1 \\
& A_{21}=80 / 90=0,888 \\
& A_{31}=70 / 90=0,777 \\
& A_{41}=60 / 90=0,666 \\
& A_{51}=60 / 90=0,666 \\
& X 3=5+3+3+2+1 \\
& A_{11}=5 / 5=1 \\
& A_{21}=3 / 5=0,6 \\
& A_{31}=3 / 5=0,6 \\
& A_{41}=2 / 5=0,4 \\
& A_{51}=1 / 5=0,2 \\
& X 4=29+33+32+36+35 \\
& A_{11}=29 / 36=0,805 \\
& A_{21}=33 / 36=0,916 \\
& A_{31}=32 / 36=0,888 \\
& A_{41}=36 / 36=1
\end{aligned}
$$


MEDIA INFORMATIKA BUDIDARMA, Vol 2, No 2, April 2018

ISSN 2614-5278 (media cetak)

ISSN 2548-8368 (media online)

Hal $10-15$

$A_{51}=35 / 36=0,972$

$X 5=5+1+3+2+2$

$A_{11}=1 / 5=0,2$

$A_{21}=1 / 1=1$

$A_{31}=1 / 3=0,333$

$A_{41}=1 / 2=0,5$

$A_{51}=1 / 2=0,5$

Hasil dari Normalisasi matriks $\mathrm{X}$ diperoleh matrik $X_{I J}^{*}$

$X_{I J}^{*}=\left[\begin{array}{ccccc}0,945 & 1 & 1 & 0,805 & 0,2 \\ 0,783 & 0,888 & 0,6 & 0,916 & 1 \\ 1 & 0,777 & 0,6 & 0.888 & 0,333 \\ 0,743 & 0,666 & 0,4 & 1 & 0,5 \\ 0,756 & 0,666 & 0,2 & 0,972 & 0,5\end{array}\right]$

3. Langkah selanjutnya mengoptimalkan atribut dengan mengalikan terhadap bobot dari setiap kriteria.

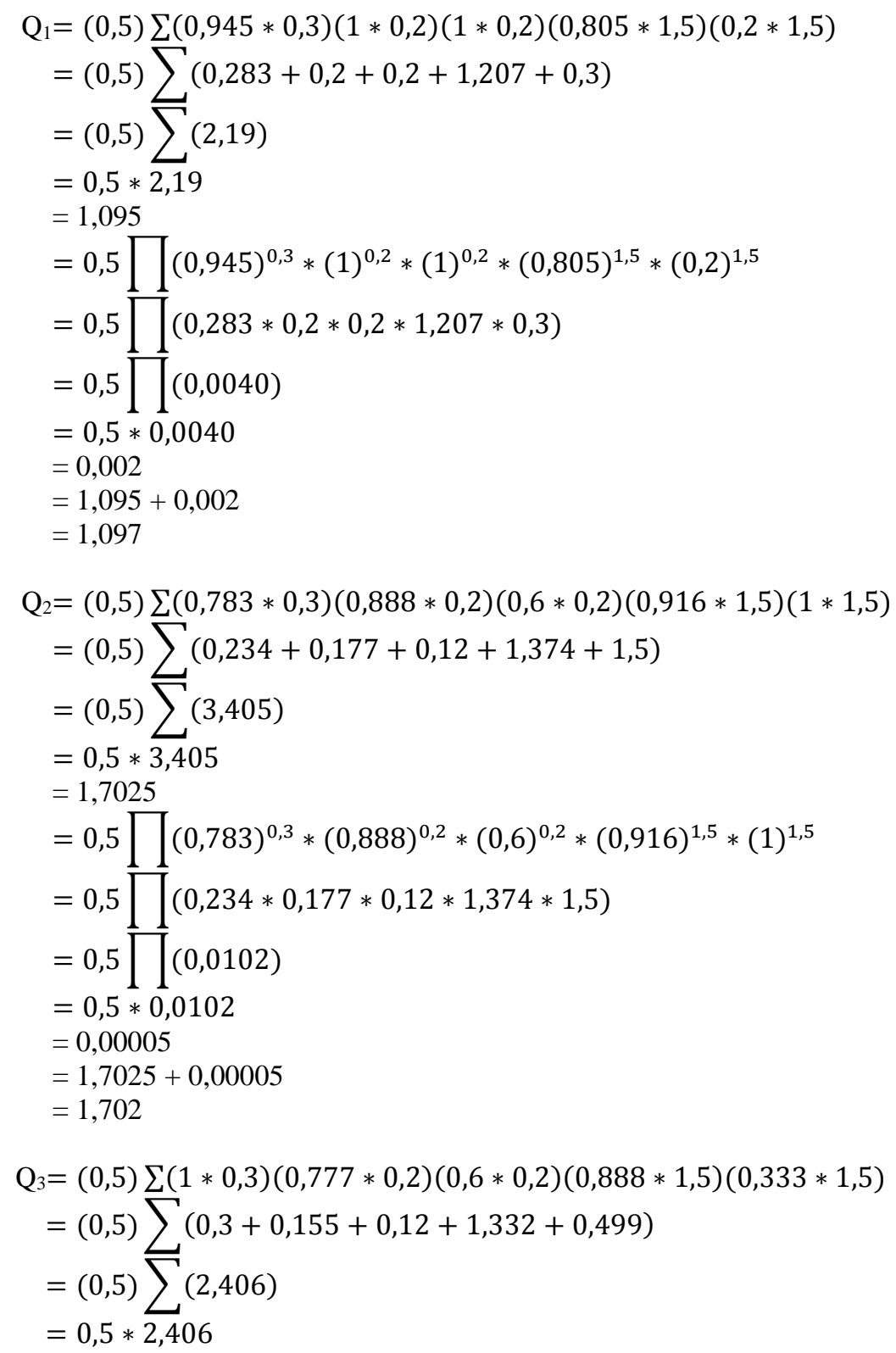




$$
\begin{aligned}
& =1,203 \\
& =0,5 \prod(1)^{0,3} *(0,777)^{0,2} *(0,6)^{0,2} *(0,888)^{1,5} *(0,333)^{1,5} \\
& =0,5 \prod(0,3 * 0,155 * 0,12 * 1,332 * 0,499) \\
& =0,5 \prod(0,0037) \\
& =0,5 * 0,0037 \\
& =0,0018 \\
& =1,203+0,0018 \\
& =1,204 \\
& \mathrm{Q}_{4}=(0,5) \sum(0,743 * 0,3)(0,666 * 0,2)(0,4 * 0,2)(1 * \quad 1,5)(0,5 * 1,5) \\
& =(0,5) \sum(0,222+0,133+0,08+1,5+0,75) \\
& =(0,5) \sum(2,685) \\
& =0,5 * 2,685 \\
& =1,3425 \\
& =0,5 \prod(0,743)^{0,3} *(0,666)^{0,2} *(0,4)^{0,2} *(1)^{1,5} *(0,5)^{1,5} \\
& =0,5 \prod(0,222 * 0,133 * 0,08 * 1,5 * 0,75) \\
& =0,5 \prod(0,0026) \\
& =0,5 * 0,0026 \\
& =0,0013 \\
& =1,3425+0,0013 \\
& =1,343 \\
& \mathrm{Q}_{5}=(0,5) \sum(0,756 * 0,3)(0,666 * 0,2)(0,2 * 0,2)(0,972 * 1,5)(0,5 * 1,5) \\
& =(0,5) \sum(0,226+0,133+0,04+1,458+0,75) \\
& =(0,5) \sum(2,607) \\
& =0,5 * 2,607 \\
& =1,303 \\
& =0,5 \prod(0,756)^{0,3} *(0,666)^{0,2} *(0,2)^{0,2} *(0,972)^{1,5} *(0,5)^{1,5} \\
& =0,5 \prod(0,226 * 0,133 * 0,04 * 1,458 * 0,75) \\
& =0,5 \prod(0,0013) \\
& =0,5 * 0,0013 \\
& =0,0006 \\
& =1,303+0,0006 \\
& =1,3036
\end{aligned}
$$

Tabel 3 merupakan hasil perhitungan akhir dan telah di lakukan perangkingan dari yang tertinggi hingga yang terendah.

Tabel 3. Hasil Rangking

\begin{tabular}{|c|c|c|}
\hline Alternatif & Hasil & Peringkat \\
\hline $\mathrm{A}_{2}$ & 1,702 & 1 \\
\hline $\mathrm{A}_{4}$ & 1,343 & 2 \\
\hline $\mathrm{A}_{5}$ & 1,303 & 3 \\
\hline $\mathrm{A}_{3}$ & 1,202 & 4 \\
\hline $\mathrm{A}_{1}$ & 1,097 & 5 \\
\hline
\end{tabular}

Terlihat pada tabel 3, bahwa $\mathrm{A}_{2}$ memiliki prioritas yang paling tinggi untuk dijadikan sebagai Guru Tetap, karena memiliki rangking yang terbaik bila dibandingkan dengan alternatif yang lainnya. 


\section{KESIMPULAN}

Dari analisa dan pembahasan yang telah dilakukan, maka dapat diambil kesimpulan,dalam pengangkatan guru tetap menggunakan metode WASPAS (Weighted Aggregated Sum Product Assessment) bisa membantu pengambil keputusan dalam memutuskan satu atau lebih dari beberapa alternatif yang harus diambil untuk dijadikan sebagai Guru Tetap dengan kriteria yang menjadi bahan pertimbangan.

\section{REFERENCES}

[1] J. Antivirus, “a. 3. 56,” vol. 10, no. 2, pp. 56-68, 2016.

[2] N. A. Syafitri, A. P. Dewi, J. T. Informatika, F. Teknik, and U. H. Oleo, "Penerapan metode,” vol. 2, no. 1, pp. 169-176, 2016.

[3] S. Chakraborty and E. K. Zavadskas, "Applications of WASPAS Method in Manufacturing Decision Making," Informatica, vol. 25, no. 1, pp. 1-20, 2014.

[4] D. R. Bahari, E. Santoso, and S. Adinugroho, "Sistem Pendukung Keputusan Penentuan Guru Berprestasi Menggunakan Fuzzy-Analytic Hierarchy Process ( F-AHP ) ( Studi Kasus : SMA Brawijaya Smart School ),” vol. 2, no. 5, pp. 2095-2101, 2018.

[5] E. K. Putra and A. I. Hadiana, "SISTEM PENDUKUNG KEPUTUSAN REKOMENDASI GURU TETAP BERDASARKAN DATA GURU HONORER BERPRESTASI MENGGUNAKAN METODE ANALYTIC HIERARCHY PROCESS ( AHP ) dan SIMPLE ADDITIVE WEIGHTING ( SAW ),” pp. 79-84, 2017.

[6] P. Simanjuntak, N. Kurniasih, and J. Simarmata, "Penentuan Kayu Terbaik Untuk Bahan Gitar Dengan Metode Weighted Aggregated Sum Product Assessment ( WASPAS )," J. Ris. Komput., vol. 5, no. 1, pp. 36-42, 2018.

[7] Fadlina, L. T. Sianturi, A. Karim, Mesran, and A. P. U. Siahaan, "Best Student Selection Using Extended Promethee II Method," Int. J. Recent Trends Eng. Res., vol. 3, no. 8, pp. 21-29, 2017.

[8] S. Dian Utami Sutiksno, P. Rufaidah, H. Ali, and W. Souisa, "A Literature Review of Strategic Marketing and The Resource Based View of The Firm," Int. J. Econ. Res., vol. 14, no. 8, pp. 59-73, 2017.

[9] S. Kusumadewi, S. Hartati, A. Harjoko, and R. Wardoyo, Fuzzy Multi-Attribute Decision Making (Fuzzy MADM). Yogyakarta: Graha Ilmu, 2006.

[10] T. Murti, L. A. Abdillah, and M. Sobri, "Sistem Penunjang Keputusan Kelayakan Pemberian Pinjaman Dengan Metode Fuzzy Tsukamoto," Semin. Nas. Inov. dan Tren (SNIT)2015, pp. 252-256, 2015.

[11] G. Ginting, Fadlina, Mesran, A. P. U. Siahaan, and R. Rahim, "Technical Approach of TOPSIS in Decision Making," Int. J. Recent Trends Eng. Res., vol. 3, no. 8, pp. 58-64, 2017.

[12] J. Simarmata, Pengenalan Teknologi Komputer dan Informasi. Yogyakarta: Andi, 2006.

[13] M. I. Setiawan et al., "Business Centre Development Model of Airport Area in Supporting Airport Sustainability in Indonesia," J. Phys. Conf. Ser., vol. 954, no. 1, p. 12024, 2018.

[14] D. Handoko, M. Mesran, S. D. Nasution, Y. Yuhandri, and H. Nurdiyanto, "Application Of Weight Sum Model (WSM) In Determining Special Allocation Funds Recipients," IJICS (International J. Informatics Comput. Sci., vol. 1, no. 2, pp. 31-35, 2017.

[15] H. Nurdiyanto and Heryanita Meilia, "SISTEM PENDUKUNG KEPUTUSAN PENENTUAN PRIORITAS PENGEMBANGAN INDUSTRI KECIL DAN MENENGAH DI LAMPUNG TENGAH MENGGUNAKAN ANALITICAL HIERARCHY PROCESS (AHP)," in Seminar Nasional Teknologi Informasi dan Multimedia 2016, 2016, no. February, pp. 1-7.

[16] Jimmy Abdel Kadar, D Agustono, and Darmawan Napitupulu, "Optimization of Candidate Selection Using Naive Bayes : Case Study in Company X Optimization of Candidate Selection Using Naive Bayes : Case Study in Company X,” J. Phys. Conf. Ser., vol. 12, no. $1,2016$.

[17] J. Antivirus, “a. 3. 56," vol. 10, no. 2, pp. 56-68, 2016

[18] N. A. Syafitri, A. P. Dewi, J. T. Informatika, F. Teknik, and U. H. Oleo, "Penerapan metode,” vol. 2, no. 1, pp. 169-176, 2016.

[19] S. Chakraborty and E. K. Zavadskas, "Applications of WASPAS Method in Manufacturing Decision Making," Informatica, vol. 25, no. 1, pp. 1-20, 2014.

[20] D. R. Bahari, E. Santoso, and S. Adinugroho, "Sistem Pendukung Keputusan Penentuan Guru Berprestasi Menggunakan Fuzzy-Analytic Hierarchy Process ( F-AHP) ( Studi Kasus : SMA Brawijaya Smart School ),” vol. 2, no. 5, pp. 2095-2101, 2018.

[21] E. K. Putra and A. I. Hadiana, "SISTEM PENDUKUNG KEPUTUSAN REKOMENDASI GURU TETAP BERDASARKAN DATA GURU HONORER BERPRESTASI MENGGUNAKAN METODE ANALYTIC HIERARCHY PROCESS ( AHP ) dan SIMPLE ADDITIVE WEIGHTING ( SAW )," pp. 79-84, 2017. 